\title{
Protocol
}

\section{Isolation and Demembranation of Xenopus Sperm Nuclei}

\author{
James W. Hazel ${ }^{1,2}$ and Jesse C. Gatlin ${ }^{1,3}$ \\ ${ }^{1}$ Department of Molecular Biology, University of Wyoming, Laramie, Wyoming 82071
}

The inherent experimental advantages of intact amphibian eggs have been exploited for several decades to advance our understanding of fundamental developmental processes and the cell cycle. Characterization of these processes at the molecular level has been greatly advanced by the use of cell-free extracts, which permit the development of biochemically tractable approaches. Demembranated Xenopus laevis sperm nuclei have been used with cell-free extracts to recapitulate cell cycle progression and to control the cell cycle state of the egg extract. This system has become an invaluable and widely used tool for studies of cell cycle regulation and many downstream events. Here, we describe a protocol, derived in part from other published protocols and modified over time, for the preparation of Xenopus sperm nuclei that can be used in a variety of in vitro assays.

It is essential that you consult the appropriate Material Safety Data Sheets and your institution's Environmental Health and Safety Office for proper handling of equipment and hazardous materials used in this protocol.

RECIPES: Please see the end of this protocol for recipes indicated by $<R>$. Additional recipes can be found online at http://cshprotocols.cshlp.org/site/recipes.

Reagents

Benzocaine $(0.5 \%)$

Dissolve in $\mathrm{ddH}_{2} \mathrm{O}$; adjust $\mathrm{pH}$ to $7.8-8.0$ with $\mathrm{NaHCO}_{3}$.

DMSO (Sigma-Aldrich 472301)

Frog husbandry water $<\mathrm{R}>$

Hormones

Human chorionic gonadotropin (HCG) (1000 IU/mL) (Sigma-Aldrich CG10)

Pregnant mare serum gonadotropin (PMSG) (100 IU/mL) (Prospec HOR-272)

Dissolve hormones in sterile $d \mathrm{dH}_{2} \mathrm{O}$ and store at $4{ }^{\circ} \mathrm{C}$.

LPC protease inhibitor cocktail (10 mg/mL leupeptin, pepstatin, chymostatin; EMD Millipore)

Dissolve in DMSO and store in $50 \mu \mathrm{L}$ aliquots at $-20^{\circ} \mathrm{C}$.

Lysolecithin (10 mg/mL; Sigma-Aldrich L4129)

Prepare freshly in $\mathrm{dd}_{2} \mathrm{O}$.

\footnotetext{
${ }^{2}$ Present address: Center for Biomedical Ethics and Society, Institute for Medicine and Public Health, Vanderbilt University Medical Center, Nashville, Tennessee 37203

${ }^{3}$ Correspondence: jgatlin@uwyo.edu

From the Xenopus collection, edited by Hazel L. Sive.

(c) 2018 Cold Spring Harbor Laboratory Press

Cite this protocol as Cold Spring Harb Protoc; doi:10.1101/pdb.prot099044
} 
J.W. Hazel and J.C. Gatlin

\section{Equipment}

Marc's modified Ringer's (MMR) for Xenopus $(1 \times)<\mathrm{R}>$

Nuclear preparation buffer $(\mathrm{NPB})<\mathrm{R}>$

$\mathrm{NPB} / \mathrm{BSA}<\mathrm{R}>$

S/S Buffer $(20 \times)<\mathrm{R}>$

$X$. laevis male frogs

This procedure can be adapted to any Xenopus species by adjusting for differences in frog and testis size. Alterations in the protocol for the smaller frog, X. tropicalis, are indicated.

Buckets for frogs (4 L, plastic, with tight-fitting lids that have holes punched for air exchange; Rubbermaid)

Centrifuge (clinical, capable of spinning $15-\mathrm{mL}$ conical tubes at $1500 \mathrm{~g}$ )

Conical tubes (plastic; $15 \mathrm{~mL}$ )

Filter paper

Fine forceps (two)

Hemocytometer

Ice bucket

Incubator $\left(16^{\circ} \mathrm{C}\right)$

Liquid nitrogen

Microcentrifuge (tabletop)

Microcentrifuge tubes $(0.5 \mathrm{~mL})$

Microcentrifuge tubes $(1.5 \mathrm{~mL})$

Microscope (for tissue culture)

Pellet pestles (disposable, plastic; Fisher 12-141-364)

Petri dish (glass, $100 \mathrm{~mm} \times 15 \mathrm{~mm}$ )

Serological pipettes (plastic, $10 \mathrm{~mL}$ ) and pipette aid

Surgical instruments (pithing needle, scalpel, blunt-ended forceps, and fine scissors)

Syringes (disposable; $1 \mathrm{~mL}$ )

Syringe needles (27-30 gauge)

1. Inject four male X. laevis frogs subcutaneously in the dorsal lymph sac with $250 \mu \mathrm{L}$ PMSG (25 IU) using a $1 \mathrm{~mL}$ syringe and $27-30$ gauge needle $\sim 72 \mathrm{~h}$ before sperm nuclei preparation. Maintain frogs in $4 \mathrm{~L}$ frog buckets containing $2 \mathrm{~L}$ frog husbandry water in a dark incubator at $16^{\circ} \mathrm{C}$.

For X. tropicalis, inject six males similarly with $100 \mu \mathrm{L}$ PMSG (10 IU) $48 \mathrm{~h}$ before sperm nuclei preparation and keep at room temperature.

2. Inject the same frogs with $125 \mu \mathrm{L} \mathrm{HCG}(125 \mathrm{IU}) \sim 24 \mathrm{~h}$ before testes isolation using the procedure described in Step 1.

For X. tropicalis, inject 50 IU HCG $\sim 24 \mathrm{~h}$ before testes isolation.

3. On the day of sperm nuclei preparation, ensure all buffers are cold and that the centrifuges are at $4^{\circ} \mathrm{C}$. Prepare lysolecithin solution and NPB solution.

With the exception of Step 11, all steps are performed with ice-cold buffers kept on ice.

4. Prepare $2 \mathrm{~L}$ of $0.05 \%$ benzocaine solution $(\mathrm{pH} 7.8-8.0)$ in a $4 \mathrm{~L}$ frog bucket. Anesthetize the frogs by immersing them in the benzocaine solution for $\sim 20-25 \mathrm{~min} \mathrm{(5-10} \mathrm{min} \mathrm{after} \mathrm{all} \mathrm{move-}$ ment has ceased). Remove the sedated frogs from the solution and pith or decapitate to ensure death.

5. To remove the testes, use a scalpel to make a vertical incision through the skin and musculature along the midline of the abdomen. Make two orthogonal incisions, one at each end of the initial 
cut, to create an "I" like shape and resect the flaps to expose the abdominal cavity (Fig. 1A). The testes are located behind the yellow fat pads on either side of the midline and present as white eggshaped bodies $\sim 1-2 \mathrm{~cm}$ in length (Fig. 1A inset). Use a pair of fine scissors to remove the testes from each frog, taking care to avoid contamination with fat tissue and place in a Petri dish containing cold $1 \times$ MMR on ice.

6. Remove any remaining vessels and fatty tissue using a pair of fine forceps and dry filter paper, being careful not to pierce or rupture the testes (compare Fig. 1B,C).

7. Rinse testes three times in cold $1 \times$ MMR in the Petri dish. Pour the buffer into the dish $(\sim 20 \mathrm{~mL}$ per rinse) and swirl. Use a pipette aid and a $10 \mathrm{~mL}$ serological pipette to remove as much buffer as possible between washes.

8. Wash two times in cold NPB ( $\sim 20 \mathrm{~mL}$ per rinse), making sure to remove as much buffer as possible between washes.

9. Using forceps, transfer two testes per $1.5 \mathrm{~mL}$ microcentrifuge tube and add $0.5 \mathrm{~mL}$ cold NPB. Keeping the tubes on ice, macerate using fine scissors and crush using a blunt, plastic pellet pestle. Homogenize the tissue vigorously.

10. Centrifuge the tubes containing the mashed testes in a tabletop microcentrifuge for $10-20 \mathrm{sec}$ to pellet the testicular tissue (take care to ensure the tubes remain cold; actively cool the centrifuge if possible). Transfer all supernatants (which contain the sperm) to a single $15 \mathrm{~mL}$ conical tube on ice. Resuspend the pelleted testicular tissue in another $0.5 \mathrm{~mL}$ of cold NPB and triturate vigorously with a cut off pipette tip (to avoid excessive shearing forces). Repeat the 10-20 sec spin and again transfer the supernatants to the same $15 \mathrm{~mL}$ conical tube.

11. Centrifuge the $15 \mathrm{~mL}$ conical tube in a clinical centrifuge at $1500 \mathrm{~g}$ for $10 \mathrm{~min}$ at $4^{\circ} \mathrm{C}$ to pellet the sperm.

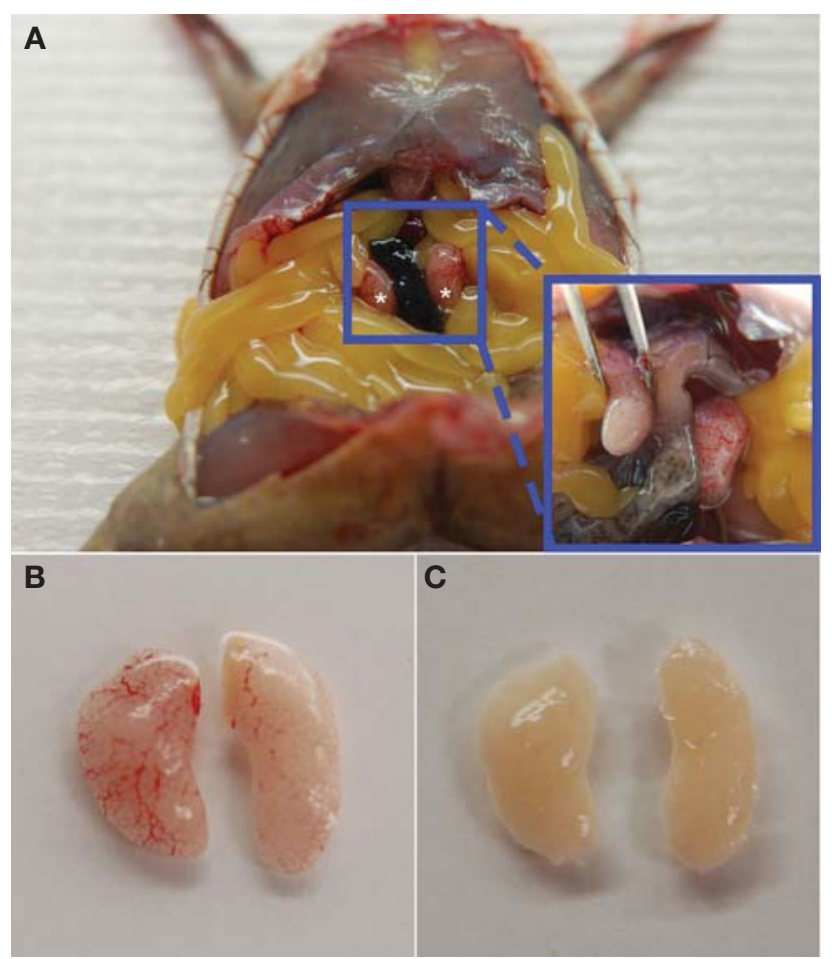

FIGURE 1. Frog testes at various stages of the protocol. $(A)$ photograph showing the anatomical location of the testes after partial resection (asterisks mark the testes and the inset shows a zoomed image with forceps tips providing scale). Photographs in $B \& C$ are of resected testes before and after removal of vessels and fat, respectively. 
J.W. Hazel and J.C. Gatlin

12. To demembranate the sperm, resuspend the sperm pellet in $1 \mathrm{~mL}$ room-temperature NPB. Add $50 \mu \mathrm{L}$ freshly prepared $10 \mathrm{mg} / \mathrm{mL}$ lysolecithin. Mix thoroughly by pipetting up and down and incubate for exactly $5 \mathrm{~min}$ at room temperature.

It is important to incubate for exactly 5 min because these conditions yield a high percentage (typically $>95 \%$ ) of demembranated sperm nuclei (as assessed by Hoechst staining) without compromising nuclei integrity.

13. Add $4 \mathrm{~mL}$ cold NPB/BSA $3 \%$ to quench the lysolecithin and then spin at $1500 \mathrm{~g}$ for $10 \mathrm{~min}$ at $4{ }^{\circ} \mathrm{C}$.

14. Aspirate the supernatant and resuspend the demembranated nuclei pellet in $2 \mathrm{~mL}$ cold NPB/BSA $0.3 \%$ and spin at $1500 \mathrm{~g}$ for $10 \mathrm{~min}$ at $4^{\circ} \mathrm{C}$.

15. Aspirate the supernatant and resuspend the pellet in $500 \mu \mathrm{L}$ cold NPB/BSA $0.3 \%+30 \%$ glycerol. Count sperm density using a hemocytometer.

For X. tropicalis, resuspend pellet in $300 \mu \mathrm{L}$.

For X. laevis, this protocol typically yields about 50,000,000 sperm nuclei per testis.

16. Dilute nuclei to the desired density in cold NPB/BSA $0.3 \%+30 \%$ glycerol and flash freeze aliquots in liquid nitrogen in $0.5 \mathrm{~mL}$ or smaller microcentrifuge tubes. Store at $-80^{\circ} \mathrm{C}$ until use.

For spindle assembly reactions, use a $100 \times$ concentration equivalent to $10^{5} \mathrm{sperm} / \mu \mathrm{L}$. Aliquots of 3-5 $\mu \mathrm{L}$ are typically stored (a volume generally sufficient for a day of experiments), but storage in larger volumes can make aliquoting more convenient. When storing in larger volumes, care should be taken to avoid excessive cycles of thawing and refreezing.

Early efforts to elucidate the cell cycle capitalized on the inherent experimental advantages of intact amphibian eggs, leading to vertical advances in our collective understanding of this fundamental biological process (Murray and Hunt 1993). However, further characterization of the cell cycle at the molecular level required different, more biochemically tractable approaches. In 1983, Manfred Lohka and Yoshio Masui introduced cell-free extracts derived from $R$. pipiens eggs as a new experimental system to study cell cycle progression and used demembranated sperm nuclei isolated from $X$. laevis to assess changes in the cell cycle state of the extract (Lohka and Masui 1983). They showed that the system was capable of recapitulating several hallmarks of cell cycle progression, including chromatin decondensation, nuclear envelope assembly, and DNA replication (see also Lohka and Masui 1984; Blow and Laskey 1986). Subsequent work showed that the cell cycle state of the egg extracts could be controlled (Lohka and Maller 1985), leading to the discovery that exogenous nuclei (or DNA/ chromatin) could induce nuclear assembly during interphase, and serve as local sites of microtubule nucleation and spindle formation in metaphase (Forbes et al. 1983; Karsenti et al. 1984; Heald et al. 1996, 1997).

The protocol presented here is based largely on methods described later by Andrew Murray (Murray 1991). Although other sources of chromatin can be used, demembranated frog sperm nuclei typically serve as a source of chromatin for nucleus and spindle assembly reactions in Xenopus egg extracts (see Protocol: Asembly of Spindles and Asters in Xenopus Egg Extracts [Field and Mitchison 2018] and Protocol: Nucleus Assembly and Import in Xenopus laevis Egg Extract [Chen and Levy 2018]). For assembly of interphase nuclei and "cycled" spindles, demembranated sperm nuclei are added to extract, which is then induced to progress into interphase, resulting in DNA synthesis and nuclear assembly (Sawin and Mitchison 1991; Desai et al. 1999). Subsequent addition of an equal volume of metaphase-arrested extract forces the extract back into mitosis, which causes chromosome condensation, disassembly of the nuclear envelope, and assembly of spindles containing chromosomes with duplicated kinetochores. 
Frog Husbandry Water

Instant Ocean Sea Salt (Instant Ocean)

$0.88 \mathrm{~g} / \mathrm{L}$

Cichlid Lake Salt (SeaChem)

$0.33 \mathrm{~g} / \mathrm{L}$

Alkaline Buffer (SeaChem)

$0.84 \mathrm{~g} / \mathrm{L}$

Acidic Buffer (SeaChem)

Equilibrium Buffer (SeaChem)

$0.33 \mathrm{~g} / \mathrm{L}$

$0.033 \mathrm{~g} / \mathrm{L}$

Prepare fresh. Dissolve components in double-distilled, reverse-osmosis, or carbonfiltered water. Sterilization is not required. Adjust the amounts of salts and buffers to ensure frog husbandry water quality parameters fall within acceptable ranges. For example, in some $X$. laevis aquatic husbandry systems, water temperature is kept at $\sim 18^{\circ} \mathrm{C}, \mathrm{pH}$ at $7.0-7.5$, conductivity at $1.2-1.8 \mathrm{mS}$, and hardness at $\sim 200 \mathrm{ppm}\left(\mathrm{CaCO}_{3}\right)$.

Marc's Modified Ringer's (MMR) for Xenopus (1X)

HEPES (free acid)

$5 \mathrm{~mm}$

EDTA

$0.1 \mathrm{~mm}$

$\mathrm{NaCl}$

$100 \mathrm{~mm}$

$\mathrm{KCl}$

$2 \mathrm{mM}$

$\mathrm{MgCl}_{2}$

$1 \mathrm{mM}$

$\mathrm{CaCl}_{2}$

$2 \mathrm{mM}$

Prepare as a $25 \times$ stock and adjust $\mathrm{pH}$ to 7.8 with $\mathrm{NaOH}$. Sterilize by autoclaving and store at $4^{\circ} \mathrm{C}$.

Nuclear Preparation Buffer (NPB) (1x)

Sucrose $(2 \mathrm{M})$

HEPES (1 M, pH 7.4)

$25 \mathrm{~mL}$

EDTA (0.5 M, pH 8.0)

$3 \mathrm{~mL}$

S/S Buffer $(20 \times)<\mathrm{R}>$

$400 \mu \mathrm{L}$

Add $\mathrm{dd}_{2} \mathrm{O}$ to $200 \mathrm{~mL}$. Make fresh, and add DTT to $1 \mathrm{~mm}$ and LPC protease inhibitor cocktail (10 mg/mL leupeptin, pepstatin, and chymostatin stock in DMSO; EMD Millipore) at $1 / 1000$ before use.

Nuclear Preparation Buffer (NPB) Solutions Containing Bovine Serum Albumin (BSA)

1. To prepare a solution of $10 \% \mathrm{BSA}$ in NPB, dissolve $2 \mathrm{~g}$ of BSA in $15 \mathrm{~mL}$ of $1 \times \mathrm{NPB}$ $<\mathrm{R}>$. Adjust the $\mathrm{pH}$ to 7.6 with $\mathrm{KOH}$, and bring the volume to $20 \mathrm{~mL}$ with $1 \times \mathrm{NPB}$.

2. To prepare a solution of $3 \%$ BSA in NPB, combine $10.5 \mathrm{~mL}$ of $1 \times \mathrm{NPB}$ with $4.5 \mathrm{~mL}$ of $10 \%$ BSA in NPB for a total of $15 \mathrm{~mL}$.

3. To prepare a solution of $0.3 \%$ BSA in NPB, combine $9 \mathrm{~mL}$ of $1 \times \mathrm{NPB}$ with $1 \mathrm{~mL}$ of $3 \%$ BSA in NPB for a total of $10 \mathrm{~mL}$.

4. To prepare a solution of $0.3 \%$ BSA in NPB plus $30 \%$ glycerol, combine $3.5 \mathrm{~mL}$ of $0.3 \%$ BSA in NPB with $1.9 \mathrm{~g}$ of glycerol, and bring the total volume to $5 \mathrm{~mL}$ with $0.3 \%$ BSA in NPB.

Prepare all NPB/BSA solutions fresh, and use the same day. Store on ice until use. 
J.W. Hazel and J.C. Gatlin

S/S Buffer (20x)

Spermidine

$127.5 \mathrm{mg}$

Spermine

$69.5 \mathrm{mg}$

Add $\mathrm{ddH}_{2} \mathrm{O}$ to $50 \mathrm{~mL}$, filter-sterilize, and store in $10-\mathrm{mL}$ aliquots at $-20^{\circ} \mathrm{C}$.

\section{ACKNOWLEDGMENTS}

The authors thank Kelly Miller for advice and comments on the manuscript and Jitender Bisht and Miroslav Tomschik for acquiring the included photographs. We would also like to express our gratitude to the programs and agencies that fund our work, namely, the National Institutes of Health (National Institute of General Medical Sciences (NIGMS) grants R01GM102428, R01GM113028), the Wyoming IDeA Networks for Biomedical Research Excellence (INBRE) program (NIGMS grant 2P20GM103432), and the Pew Biomedical Scholars program.

\section{REFERENCES}

Blow JJ, Laskey RA. 1986. Initiation of DNA replication in nuclei and purified DNA by a cell-free extract of Xenopus eggs. Cell 47: 577-587.

Chen P, Levy DL. 2018. Nucleus assembly and import in Xenopus laevis egg extract. Cold Spring Harb Protoc doi: 10.1101/pdb.prot097196.

Desai A, Murray AW, Mitchison T, Walczak CE. 1999. The use of Xenopus egg extracts to study mitotic spindle assembly and function. Methods Cell Biol 61: 385-412.

Field CM, Mitchison TJ. 2018. Assembly of spindles and asters in Xenopus egg extracts. Cold Spring Harb Protoc doi: 10.1101/pdb.prot099796.

Forbes DJ, Kirschner MW, Newport JW. 1983. Spontaneous formation of nucleus-like structures around bacteriophage DNA microinjected into Xenopus eggs. Cell 34: 13-23.

Heald R, Tournebize R, Blank T, Sandaltzopoulos R, Becker P, Hyman A, Karsenti E. 1996. Self-organization of microtubules into bipolar spindles around artificial chromosomes in Xenopus egg extracts. Nature 382: $420-425$.

Heald R, Tournebize R, Habermann A, Karsenti E, Hyman A. 1997. Spindle assembly in Xenopus egg extracts: Respective roles of centrosomes and microtubule self-organization. J Cell Biol 138: 615-628.
Karsenti E, Newport J, Hubble R, Kirschner M. 1984. Interconversion of metaphase and interphase microtubule arrays, as studied by the injection of centrosomes and nuclei into Xenopus eggs. J Cell Biol 98: 1730-1745.

Lohka MJ, Maller JL. 1985. Induction of nuclear envelope breakdown, chromosome condensation, and spindle formation in cell-free extracts. $J$ Cell Biol 101: 518-523.

Lohka MJ, Masui Y. 1983. Formation in vitro of sperm pronuclei and mitotic chromosomes induced by amphibian ooplasmic components. Science 220: 719-721.

Lohka MJ, Masui Y. 1984. Roles of cytosol and cytoplasmic particles in nuclear envelope assembly and sperm pronuclear formation in cellfree preparations from amphibian eggs. J Cell Biol 98: 1222-1230.

Murray AW. 1991. Cell cycle extracts. Methods Cell Biol 36: 581-605.

Murray AW, Hunt T. 1993. The cell cycle: An introduction. W.H. Freeman, New York. xii, $251 \mathrm{pp}$.

Sawin KE, Mitchison TJ. 1991. Mitotic spindle assembly by two different pathways in vitro. J Cell Biol 112: 925-940. 


\section{Isolation and Demembranation of Xenopus Sperm Nuclei}

James W. Hazel and Jesse C. Gatlin

Cold Spring Harb Protoc; doi: 10.1101/pdb.prot099044 originally published online February 7, 2018

\begin{tabular}{rc}
$\begin{array}{r}\text { Email Alerting } \\
\text { Service }\end{array}$ & Receive free email alerts when new articles cite this article - click here. \\
\hline $\begin{array}{c}\text { Subject } \\
\text { Categories }\end{array}$ & $\begin{array}{c}\text { Browse articles on similar topics from Cold Spring Harbor Protocols. } \\
\text { Subcellular Fractionation (88 articles) } \\
\text { Xenopus (210 articles) }\end{array}$ \\
\hline
\end{tabular}

